Check for updates

Cite this: Chem. Sci., 2019, 10, 6140

๑ All publication charges for this article have been paid for by the Royal Society of Chemistry Accepted 13th May 2019

DOI: $10.1039 / c 9 s c 01422 e$

rsc.li/chemical-science
Received 22nd March 2019

\section{Temperature-dependent interchromophoric interaction in a fluorescent pyrene-based metal-organic framework $\dagger$}

\author{
Andrzej Gtadysiak, ${ }^{a}$ Tu N. Nguyen, (D) a Richard Bounds, ${ }^{b}$ Anna Zacharia, ${ }^{c}$ \\ Grigorios Itskos, ${ }^{c}$ Jeffrey A. Reimer (iD ${ }^{b}$ and Kyriakos C. Stylianou (iD) *a
}

\begin{abstract}
Compounds exhibiting tuneable fluorescence emission upon heating or cooling are considered smart materials as their optical properties can be exquisitely controlled by adjusting the external temperature. Herein, we report such a material, which is a porous pyrene-based metal-organic framework with a chemical formula of $\left[\mathrm{Mg}_{1.5}(\mathrm{HTBAPy})\left(\mathrm{H}_{2} \mathrm{O}\right)_{2}\right] \cdot 3 \mathrm{DMF}\left(\mathrm{H}_{4}\right.$ TBAPy = 1,3,6,8-tetrakis( $p$-benzoic acid)pyrene), named SION-7. The bulk solid material of SION-7 can display either monomer or excimer fluorescence emission due to the temperature-dependent extent of interchromophoric interactions between the $\mathrm{HTBAPy}^{3-}$ ligands within the framework. Consequently, the fluorescence emission colours gradually change from blue at low temperature $(80 \mathrm{~K})$ to yellow-green at high temperature $(450 \mathrm{~K})$. Interestingly, while kept in a relatively wide temperature range of $80-200 \mathrm{~K}, \mathrm{SION}-7$ displays a structured monomerlike spectrum and its colour changes reversibly from deep to light blue. Ex situ variable-temperature (100-350 K) single-crystal X-ray diffractometry studies revealed the impact of solvent content on the optical properties of SION-7, and illustrated the correlation between the position of the phenylene groups of the HTBAPy ${ }^{3-}$ ligands at different temperatures and the interchromophoric interaction. Our study demonstrates a step forward towards the design of tuneable thermofluorochromic materials sought by optoelectronics.
\end{abstract}

\section{Introduction}

Interchromophoric interactions play a crucial role in the optical properties of materials that are assembled from multiple chromophores. For non-interacting chromophores, after photoexcitation, the excited electron can simply relax to the ground state via fluorescence and/or via non-radiative processes such as internal conversion and intersystem crossing. When the chromophores are coupled, e.g. when they are positioned in proximity to each other and with a suitable orientation, however, an excited chromophore can pair up with a nearby unexcited chromophore to form an excimer (excited dimer), which often displays emission that is markedly different than the one of the chromophore itself. ${ }^{1}$ When the components of the interacting chromophores are of different chemical identity,

\footnotetext{
${ }^{a}$ Laboratory of Molecular Simulation (LSMO), Institut des Sciences et Ingénierie Chimiques (ISIC), Ecole Polytechnique Fédérale de Lausanne (EPFL Valais), Rue de l'Industrie 17, 1951 Sion, Switzerland. E-mail: kyriakos.stylianou@epfl.ch

${ }^{b}$ Department of Chemical and Biomolecular Engineering, University of California, Berkeley 94720, USA

'Experimental Condensed Matter Physics Laboratory, Department of Physics, University of Cyprus, Nicosia 1678, Cyprus

$\dagger$ Electronic supplementary information (ESI) available. CCDC 1897075 and 1897076. For ESI and crystallographic data in CIF or other electronic format see DOI: $10.1039 / \mathrm{c} 9 \mathrm{sc} 01422 \mathrm{e}$
}

the entity is called exciplex (excited complex). Excimers and exciplexes have found numerous applications. They can be used to estimate the distance between biomolecules grafted with organic chromophores, ${ }^{2}$ while their application in chemical sensing or luminescent thermometry has also been widely studied. ${ }^{3}$ In addition, while embedded in a polymeric matrix, they can serve as wavelength switchable microlasers. ${ }^{4}$

Among fluorescent organic compounds, pyrene and its derivatives are canonical examples that display excimer fluorescence, which is often a structureless emission band in highconcentration solutions. When the solution is diluted, the structured emission band at lower wavelengths originating from the unassociated monomer becomes more dominant as the interaction between the pyrene chromophores is diminishing. ${ }^{5}$ This principle of interchromophoric interaction is also applied for pyrene and its derivatives in the solid state. ${ }^{6}$ Apparently, if this interaction can be finely controlled, materials with desired optical properties can be rationally designed. In fact, efforts in investigating the interchromophoric interaction in pyrene-based organic and inorganic solid materials have been noticed. ${ }^{7}$ For the latter, recent focus is on pyrene-based metal-organic frameworks (MOFs). ${ }^{8}$

MOFs are crystalline materials which often exhibit high porosity and structural tuneability, ${ }^{9}$ and can be synthesised in a wide range of topologies. ${ }^{10}$ They have found numerous 
applications, including methane storage, ${ }^{\mathbf{1 1}}$ heterogeneous catalysis $^{12}$ as well as temperature, ${ }^{13}$ pressure, ${ }^{14}$ and chemical sensing..$^{13,15}$ Optical properties of MOFs, such as their UV/vis absorption, are known to be finely tuneable by external stimuli, e.g. chemical species ${ }^{16}$ temperature ${ }^{17}$ or pressure. ${ }^{18}$ The fluorescence of MOFs has been equally intensely investigated. ${ }^{19}$ This arises from the fact that in many instances, the usefulness of MOF materials stems from their fluorescence emission, which in turn is heavily dependent on the interactions between the chromophores. Excimer emission of MOF materials due to interchromophoric interactions have been observed in several cases. $^{3 a, b, 20}$ In particular, the extent of the interchromophoric interaction in several MOFs was found to be topologydependent as each MOF displayed different concentration, distance, and mutual orientation of the ligands. ${ }^{7 c, d}$ However, it is still unclear how the interchromophoric interaction can be controlled within each porous material; therefore, this is still an attractive platform for further investigation, and is the topic of this work.

Herein, we report a porous MOF, named SION-7, based on $\mathrm{Mg}^{\mathrm{II}}$ and $\mathrm{H}_{4}$ TBAPy (1,3,6,8-tetrakis( $p$-benzoic acid)pyrene). The intensity and position of the fluorescence emission band of SION-7 is temperature-dependent, with a structured emission spectrum characteristic for pyrene-derivative monomers at low temperature, which gradually transforms to a structureless redshifted emission spectrum when the temperature is increased, indicating the presence of excimers due to interchromophoric interaction. Ex situ variable-temperature (VT) single-crystal Xray diffractometry (SCXRD) studies were performed providing insights into the relationship between the structure and the temperature-dependent interaction between the pyrene moieties, and will be discussed in detail.

\section{Experimental section}

\section{Procedures and materials}

All manipulations were performed under aerobic conditions using chemicals and solvents as received without further purification. The compound $\mathrm{H}_{4}$ TBAPy was synthesised using a previously reported procedure. ${ }^{8 a}$

\section{Synthesis of SION-7}

With the chemical formula of $\left[\mathrm{Mg}_{1.5}(\mathrm{HTBAPy})\left(\mathrm{H}_{2} \mathrm{O}\right)_{2}\right] \cdot 3 \mathrm{DMF}$, SION-7 was synthesised from the reaction of $10.0 \mathrm{mg}(0.0390$ $\mathrm{mmol})$ of $\mathrm{Mg}\left(\mathrm{NO}_{3}\right)_{2} \cdot 6 \mathrm{H}_{2} \mathrm{O}$ and $10.0 \mathrm{mg}(0.0146 \mathrm{mmol})$ of $\mathrm{H}_{4}$ TBAPy in a mixture composed of $5.0 \mathrm{~mL}$ of $\mathrm{N}, \mathrm{N}$-dimethylformamide (DMF), $1.0 \mathrm{~mL}$ of $\mathrm{H}_{2} \mathrm{O}$ and $80 \mu \mathrm{L}$ of $\mathrm{HCl}$ (Techn., $32 \%$ ) held at $393 \mathrm{~K}$ for 72 hours. Block-shape single crystals of SION-7 suitable for SCXRD analysis were obtained in a $47.8 \%$ yield $(6.8 \mathrm{mg})$. The activated sample, SION-7a, was prepared by heating the dried powdered sample of SION-7 at $403 \mathrm{~K}$ under dynamic vacuum for 8 hours.

\section{Single-crystal X-ray diffraction (SCXRD)}

A high-quality single crystal of SION-7 was isolated from the mother liquor, and mounted onto the PILATUS@SNBL diffractometer at the BM01 beamline (European Synchrotron Radiation Facility, Grenoble, France). ${ }^{21}$ The crystal was kept at $100 \mathrm{~K}$, probed with X-rays, and the intensities of Bragg reflections were recorded with the PILATUS2M detector. Raw data were processed with CrysAlisPro (v. 1.171.38.43) program suite, ${ }^{22}$ and the empirical absorption correction was performed using spherical harmonics, implemented in SCALE3 ABSPACK scaling algorithm. Crystal structure was solved with the SHELXT structure solution program using Intrinsic Phasing, ${ }^{23}$ and refined with the SHELXL refinement package using leastsquares minimisation, ${ }^{\mathbf{2 4}}$ implemented in the Olex2 program suite. ${ }^{25}$ Structure simplification and net classification was performed using the TOPOS Pro program suite. ${ }^{26}$ Crystal structurederived pore volume as well as contribution of the disordered solvent molecules found in the structural voids to the measured structure factors were quantified with the solvent mask procedure implemented in Olex $2 .{ }^{27}$ The integrated electron density found in the pores was interpreted in terms of number of DMF molecules by comparison to the electron count of the latter $\left(\mathrm{C}_{3} \mathrm{H}_{7} \mathrm{NO}, 40 \mathrm{e}^{-}\right)$.

Variable-temperature (VT) SCXRD measurements were performed by modifying the abovementioned procedure. The temperature was controlled with a Cryostream 700+ nitrogen blower. Full sphere of reflections was recorded at each temperature point, and the corresponding crystal structures were further solved and refined. Eventually, crystal structure of SION-7 was determined at 100, 150, 200, 250, 270, 293, 310, 330, and $350 \mathrm{~K}$ on heating and subsequent cooling.

\section{Other characterisation techniques}

Powder X-ray diffraction (PXRD) patterns were recorded using synchrotron radiation at the BM31 beamline (ESRF, Grenoble, France). In the in situ VT PXRD experiment bulk powder of the as-synthesised SION-7 was packed into a glass capillary and heated at a rate of $3 \mathrm{~K} \mathrm{~min}^{-1}$ from room temperature to $600 \mathrm{~K}$. The Le Bail fit of the pattern recorded at room temperature was performed with the FullProf program suite. ${ }^{28}$

Thermogravimetric analysis (TGA) was performed with the TGA Q500 instrument on a sample heated at a constant rate of 5 $\mathrm{K} \min ^{-1}$ with air acting as carrier gas.

Gravimetric gas sorption measurements were performed using the Intelligent Gravimetric Analyzer Instrument (IGA) from Hiden.

${ }^{13} \mathrm{C}$ CP-MAS solid-state NMR spectra were recorded at a 700 $\mathrm{MHz}$ spectrometer with a rotor spinning frequency of $8 \mathrm{kHz}$. The density functional theory (DFT)-based code CASTEP was used to calculate the predicted chemical shifts.

Fourier-transform infrared (FT-IR) spectra were recorded on a PerkinElmer Spectrum Two FT-IR spectrometer.

Diffuse reflectance UV/vis spectra were recorded on a PerkinElmer Lambda $950 \mathrm{~S}$ spectrometer.

VT fluorescence spectra were recorded in the $80-450 \mathrm{~K}$ temperature range in steps of $10 \mathrm{~K}(80-200 \mathrm{~K}$ range) or $25 \mathrm{~K}$ (200-450 K range), as well as in the $80-200 \mathrm{~K}$ temperature range in steps of $10 \mathrm{~K}$, covering the range of wavelengths of 415$720 \mathrm{~nm}$, using the excitation wavelength of $405 \mathrm{~nm}$. In addition, 
the fluorescence spectra were expressed in the RGB coordinates using the Commission Internationale de l'Eclairage (CIE)-1931 standard. Fluorescence decays monitoring the peak emission were fitted with double-exponentials yielding weighted average lifetimes.

\section{Results and discussion}

\section{Synthesis and crystal structure analysis}

The synthesis of SION-7 was performed under solvothermal reaction conditions. $\mathrm{Mg}^{2+}$ was chosen to form the MOF as it is diamagnetic and does not cause the quenching of fluorescence often observed with paramagnetic metal ions. The presence of a small amount of $\mathrm{HCl}$ is critical for the reaction and it is believed to act as the reaction modulator that facilitates crystal growth by adjusting the reaction kinetics. The molar ratios of the reactants were screened to obtain the phase-pure product. The synthesis procedure is slightly different to that previously reported, ${ }^{29}$ therefore, the formulae of the resultant MOFs differ.

The structure of SION-7 was revealed from the SCXRD measurement. SION-7 crystallises in the triclinic space group $P \overline{1}$. The asymmetric unit comprises one partially protonated $\mathrm{HTBAPy}^{3-}$ ligand, two $\mathrm{Mg}$ atoms (one of which sits on a special position with 0.5-occupancy), and two coordinated $\mathrm{H}_{2} \mathrm{O}$ molecules (Fig. S1†). SION-7 is a 2-dimensional structure in which $\mathrm{Mg}-\mathrm{O}$ trinuclear clusters (Fig. 1a) link pairs of mutually parallel
HTBAPy $^{3-}$ ligands into infinite layers (Fig. 1b). In the third dimension, the clusters form supramolecular chains along the $a$-axis held together by hydrogen bonds (Fig. S2 $\dagger$ ). Within each of these clusters, Mg1 assumes the central position (it is localised on an inversion centre), $\mathrm{Mg} 2$ is present in form of two symmetrical equivalents, and both $\mathrm{Mg} 1$ and $\mathrm{Mg} 2$ adopt an octahedral coordination geometry with the coordination number 6 (Fig. 1a). Such clusters are not uncommon in the coordination chemistry of magnesium. ${ }^{30}$ Four HTBAPy ${ }^{3-}$ positioned in the middle of the $\mathrm{Mg}_{3}$-cluster use both their carboxylate O-atoms to bind to $\mathrm{Mg} 1$ and $\mathrm{Mg} 2$ through the $\eta^{1}: \eta^{1}$ bridging mode, while the other four HTBAPy ${ }^{3-}$ ligands are $\eta^{1}$ coordinated to $\mathrm{Mg} 2$ through a single carboxylate O-atom (Fig. 1c). Analogous types of positions are assumed by coordinated $\mathrm{H}_{2} \mathrm{O}$ molecules, with two of them in the middle of the $\mathrm{Mg}_{3}$-cluster being $\eta^{1}: \eta^{1}$-bridging and two others at its extremities being $\eta^{1}$-coordinated. In addition, HTBAPy ${ }^{3-}$ ligands $\eta^{1}$ coordinated to $\mathrm{Mg} 2$ are bound with strong hydrogen bonds to the bridging $\mathrm{H}_{2} \mathrm{O}$ molecules (Fig. S3 $\dagger$ ). Pairs of $\mathrm{HTBAPy}^{3-}$ ligands are linked covalently by coordination bonds (Fig. 1d); the 2D layers, in turn, are stacked on the top of one another with non-covalent (H-bonds, $\pi-\pi$ stacking and van der Waals) interactions. The layered structure of SION-7 can be topologically interpreted considering the $\mathrm{Mg}_{3}$-clusters as 8-coordinated nodes, and HTBAPy $^{3-}$ ligands as 4-coordinated nodes. This

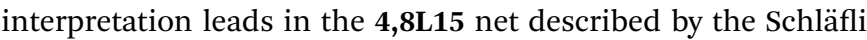
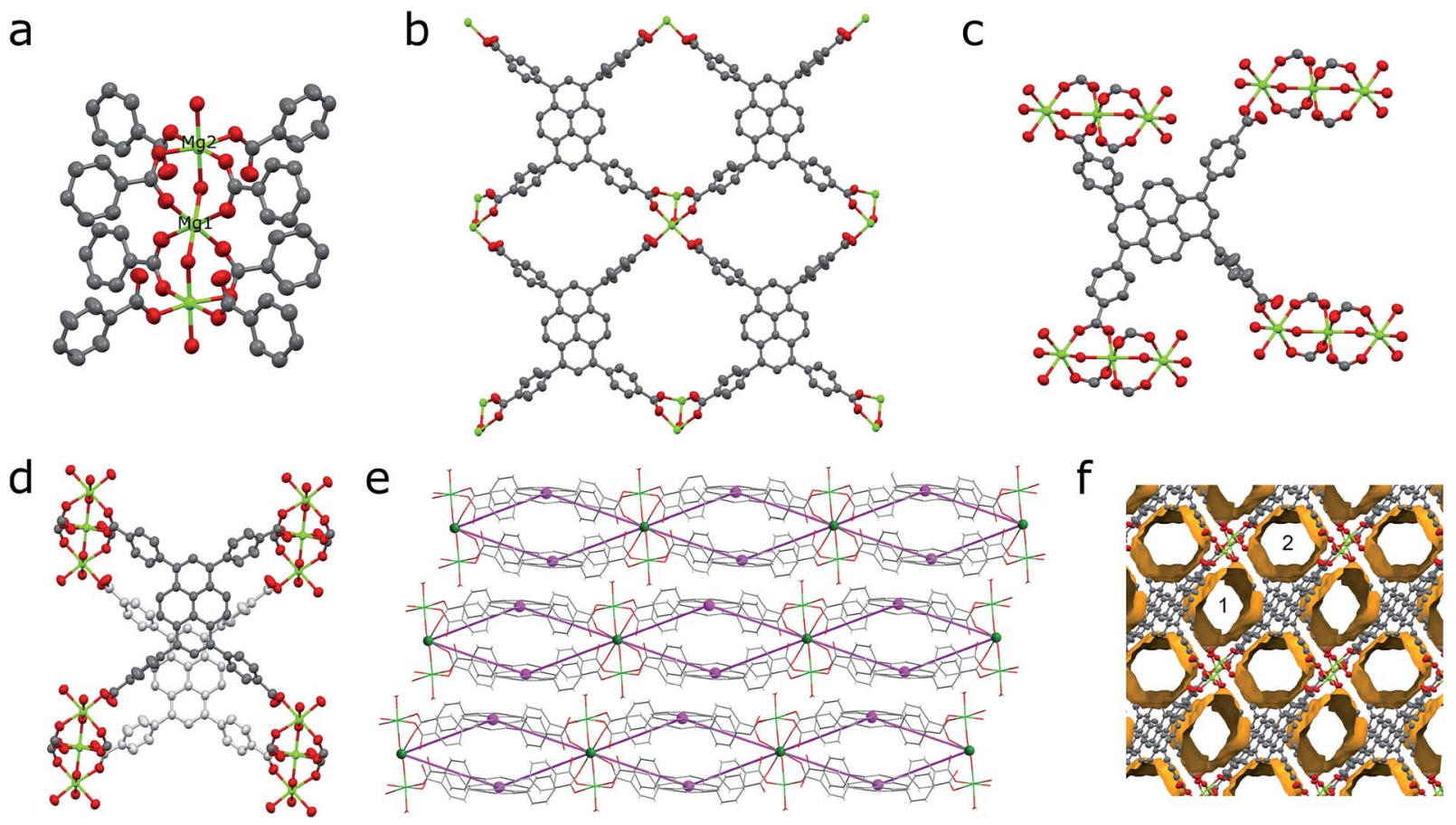

Fig. 1 (a) Centrosymmetrical $\mathrm{Mg}_{3}$-cluster constituting the structure of SION-7. Mg1, positioned in its middle, sits on an inversion centre, while $\mathrm{Mg} 2$ is on a general position. (b) Top part of a 2-dimensional layer constructed from HTBAPy ${ }^{3-}$ ligands joined together by $\mathrm{Mg}_{3}-\mathrm{Clusters.}$ (c) Coordination environment of an HTBAPy ${ }^{3-}$ ligand with $\eta^{1}: \eta^{1}$-bridging and $\eta^{1}$-coordination modes. (d) A pair of HTBAPy ${ }^{3-}$ ligands linked by $\mathrm{a} \mathrm{Mg}_{3}$-cluster viewed parallel to the pyrene cores (the ligand positioned in the bottom is shown in pale grey). Offset of pyrene cores is noticeable. (e) 2-Dimensional layers viewed along the [110] direction overlaid with the topological scheme of the underlying 4,8L15 net. (f) The system of structural voids, including pore 1 and pore 2, viewed along the a-axis. Colour code: C, black; O, red; Mg, light green; 4-c node, purple; 8-c node, green. $\mathrm{H}$ atoms are omitted for clarity. 
symbol of $\left(4^{20} \cdot 6^{8}\right)\left(4^{6}\right)_{2}$ (Fig. 1e and S4†)..$^{31}$ The structure of SION7 contains infinitely propagating structural voids, and two distinct pores, pore 1 and pore 2 (Fig. 1f), account for the total of $41.1 \%$ of the unit cell's volume and accommodate three heavily disordered DMF molecules.

\section{Thermal stability and phase transitions}

Le Bail fit confirmed the phase purity of SION-7 (Fig. S5†). The structure of SION-7 is retained on heating up to $456 \mathrm{~K}$, as inferred from in situ VT PXRD measurements (Fig. 2a). At this temperature a phase transition occurs towards SION-7a endowed with a markedly different powder pattern. Significant change of periodicity shown by PXRD indicates a structural rearrangement taking place upon the phase transition. The phase transition temperature of $456 \mathrm{~K}$ is also registered by the TGA: this is the point up to which all three guest DMF molecules are released in a gradual way (Fig. S6†). Therefore, we reason that SION-7a is the activated form of SION-7, i.e. the one of the same chemical composition, but with solvent-free pores. This is further confirmed by the gravimetric sorption measurements, which show that SION-7a is porous to $\mathrm{N}_{2}$ at $77 \mathrm{~K}$ and $1 \mathrm{bar}$, and $\mathrm{CH}_{4}$ (Fig. S7 $\dagger$ ), and its BET surface area amounts to $580 \mathrm{~m}^{2} \mathrm{~g}^{-1}$. The structure-derived pore volume $\left(0.30 \mathrm{~cm}^{3} \mathrm{~g}^{-1}\right)$ is consistent with the pore volume obtained from the $\mathrm{N}_{2}$-adsorption isotherm $\left(0.22 \mathrm{~cm}^{3} \mathrm{~g}^{-1}\right)$. Additionally, the ${ }^{13} \mathrm{C}$ CP-MAS solidstate NMR spectrum of the as-made SION-7, successfully predicted with the DFT-based CASTEP code, displays the same resonances as the spectrum of the activated SION-7a does (Fig. 2b), and the FT-IR spectra of SION-7 and SION-7a are nearly identical (Fig. S8 $\dagger$ ), hence upon activation the chemical identity of the material is retained. This activation, however, is irreversible as submersion of SION-7a in liquid DMF does not lead to the regeneration of SION-7 (confirmed by PXRD). SION-7a is stable on heating up to around $700 \mathrm{~K}$, when the framework decomposition starts (TGA, Fig. S6†). In situ activation at elevated temperatures under vacuum leads to the breakdown of single crystals of SION-7 (Fig. S9†), thus preventing us from the study of SION-7a with SCXRD.

\section{Optical properties}

Bulk SION-7 powder has a pale yellow colour, which manifests itself in a diffuse reflectance UV/vis spectrum as a broad peak centred at $413 \mathrm{~nm}$. Upon activation, the colour of SION-7a changes to deep yellow, which is also reflected by a slight shift of the absorption band towards a maximum at $434 \mathrm{~nm}$ (Fig. S10†). By exciting SION-7 near its absorption maximum at rt. results in a fluorescence emission with a broad peak centred at around $500 \mathrm{~nm}$ and with the calculated quantum yield of $1.59(2) \%$. The shift observed in the UV/vis diffuse reflectance spectra of SION-7 and SION-7a as well as the widely studied fluorescent properties of the pyrene molecule and its derivatives prompted us to thoroughly investigate the emission of SION-7 using variable-temperature fluorescence spectroscopy. ${ }^{15 c, 33}$

\section{Temperature-dependent interchromophoric interaction}

Solid-state fluorescence emission spectra of SION-7 measured in the $80-450 \mathrm{~K}$ temperature range on heating and cooling are presented in Fig. 3a. At $80 \mathrm{~K}$, SION-7 exhibits a broad fluorescence spectrum including distinctly structured bands at $440 \mathrm{~nm}$ and $465 \mathrm{~nm}$, characteristic for the $\pi-\pi^{*}$ transitions of pyrenederived monomers. ${ }^{5}$ Upon heating, this emission decreases in intensity and the structureless emission bands characteristic of the excimer become more dominant. At $450 \mathrm{~K}$, the excimer emission with the peak at $525 \mathrm{~nm}$ can be observed. A similar transition was reported in thin films of high-temperature polymorph of pyrene,$^{34}$ but not in a bulk solid material. This
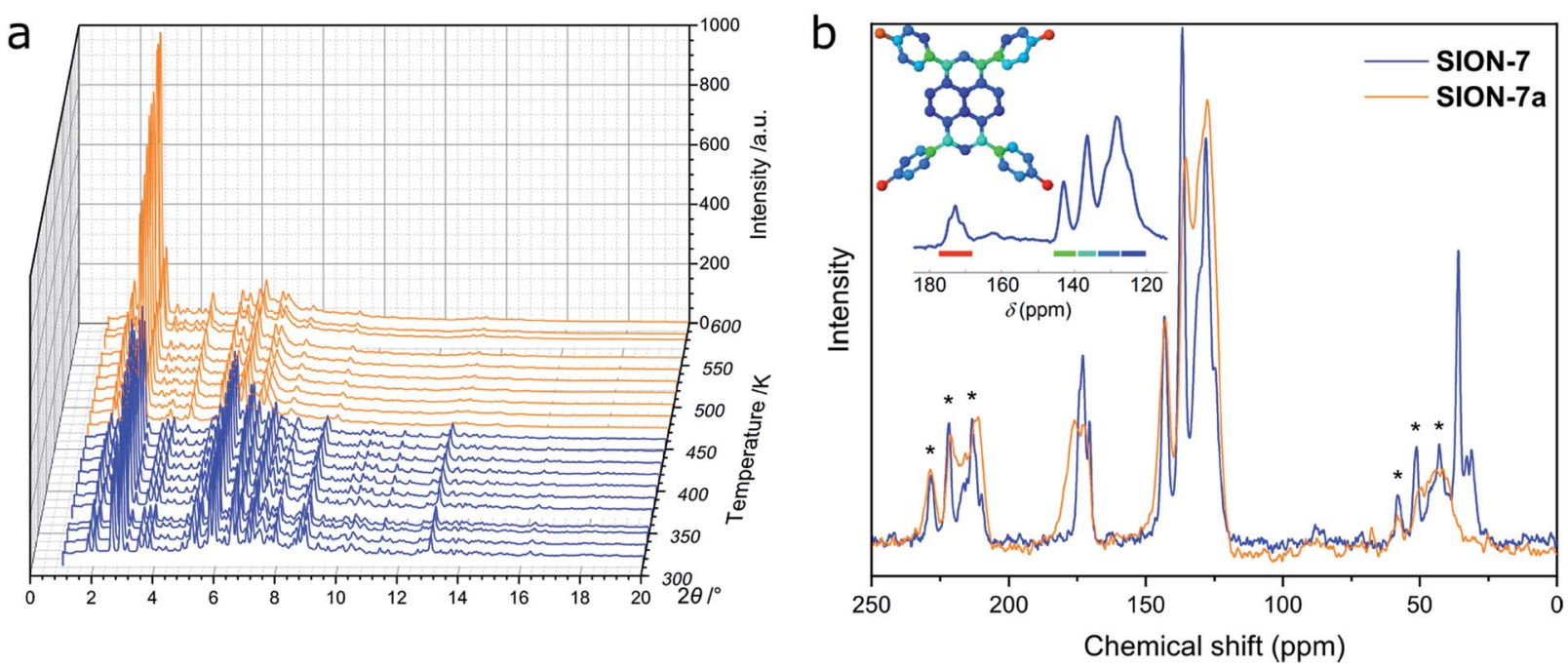

Fig. 2 (a) VT PXRD patterns recorded from SION-7 on heating. Significant changes in the positions and intensities of the Bragg peaks at $456 \mathrm{~K}$ marking the phase transition towards SION-7a are clearly noticeable. (b) ${ }^{13} \mathrm{C} \mathrm{CP-MAS} \mathrm{solid-state} \mathrm{NMR} \mathrm{spectrum} \mathrm{of} \mathrm{SION-7a} \mathrm{compared} \mathrm{to} \mathrm{that} \mathrm{of}$ SION-7. Asterisks refer to spinning sidebands. Peak assignment: $170-180$ ppm: carbonyl C of HTBAPy ${ }^{3-}, 161.8$ ppm: carbonyl C of DMF, ${ }^{32} 120-$

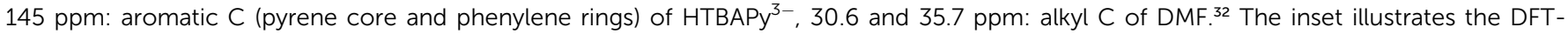
calculated resonances and their assignment to the structure. 

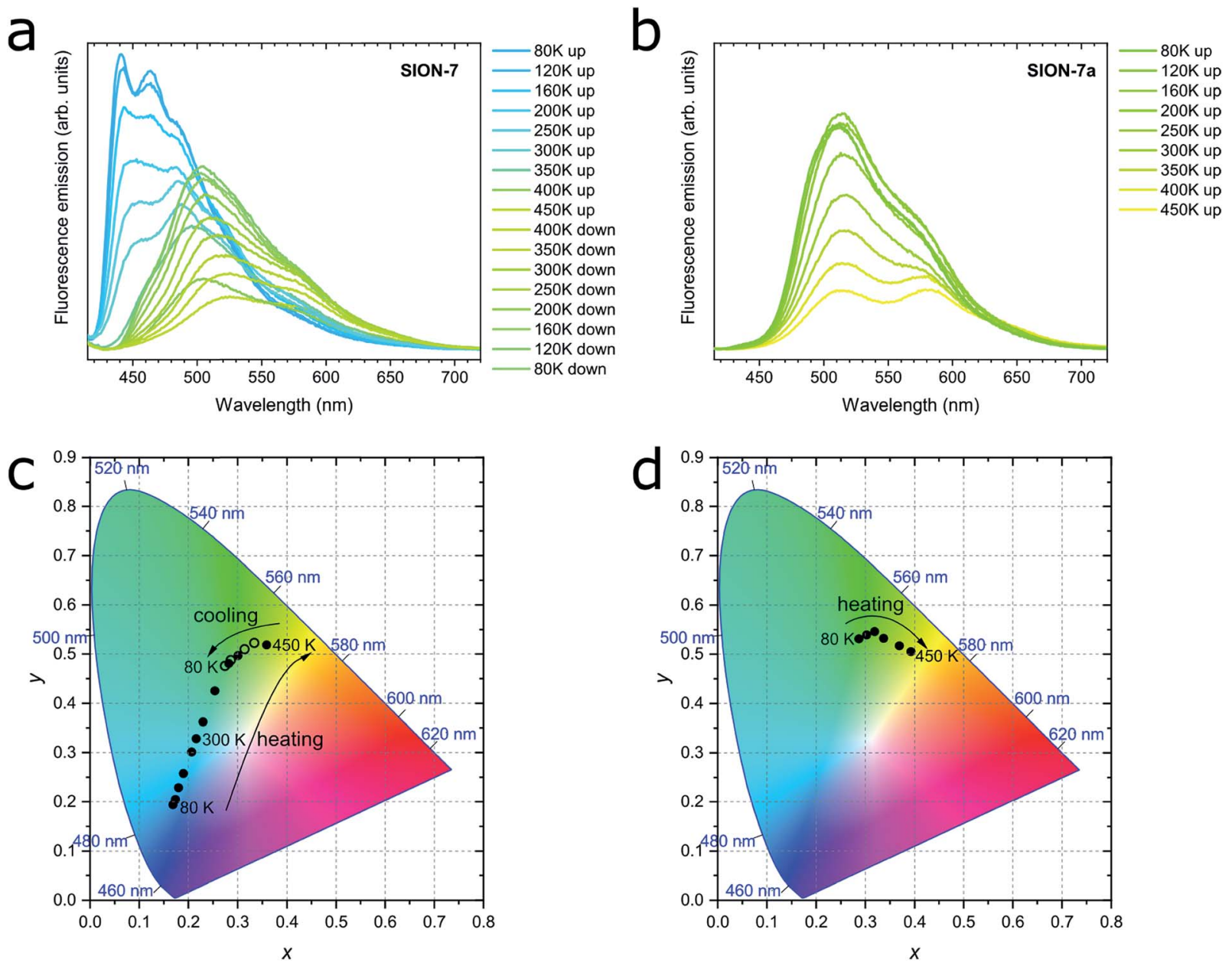

Fig. 3 (a) Fluorescence spectra of SION-7 measured in the $80-450 \mathrm{~K}$ temperature range on heating and cooling. (b) Fluorescence spectra of SION-7a measured in the 80-450 K temperature range on heating. In both panels the colours of the curves represent the perception of a given spectrum by human colour vision, as determined with the CIE-1931 standard. $\lambda_{\mathrm{ex}}=405 \mathrm{~nm}$. (c) ClE-1931 chromaticity diagram displaying the colour coordinates $(x, y)$ of the fluorescence from SION-7 during heating (filled circles) and cooling (empty circles) in the $80-450 \mathrm{~K}$ temperature range. (d) CIE-1931 chromaticity diagram of the fluorescence from SION-7a during heating from 80 to $450 \mathrm{~K}$.

result clearly demonstrates the varying degree of interchromophoric interaction within SION-7 as a function of temperature. On subsequent cooling, the monomer spectrum is not recovered, but instead the excimer emission enhances its intensity and blue-shifts its peak to $505 \mathrm{~nm}$ at $80 \mathrm{~K}$ (Fig. 3a). CIE-1931 chromaticity diagram of the SION-7 fluorescence shows the gradual transition of the emission colour from blue at low temperatures to yellow-green at higher temperatures (Fig. 3c and $\mathrm{S} 11 \dagger$ ). Although MOFs responding to external pressure ${ }^{35}$ and chemical species ${ }^{36}$ alter the colour of their fluorescence to a similarly strong extent, such drastic changes occurring in MOFs as a function of temperature are relatively rare. ${ }^{37}$ Further heating and cooling of the material gives a very similar emission and intensity profile as in the first thermal sequence (Fig. S12a, $c$ and $\left.e^{\dagger}\right)$, in which the fluorescence intensity always decreases upon heating, but is brought back to the initial values on cooling (Fig. S12b, d and $f \dagger$ ). This is expected since at higher temperatures more vibrational levels are available, and hence more non-radiative decay processes can occur. Emission lifetimes of SION-7 at different temperatures within the first thermal sequence are summarised in Table 1 . It is apparent that upon heating, the increased population of excimers leads to the lengthening of the fluorescence dynamics. This observation is in agreement with a previous report in which the excimer formation in pyrene-based MOFs enhances the lifetime of the emissive excited states as compared to the free linker. ${ }^{7 c}$

Table 1 Average fluorescence lifetimes of SION-7 at different temperatures upon heating and cooling

\begin{tabular}{lll}
\hline & \multicolumn{2}{l}{ Average lifetime (ns) } \\
\cline { 2 - 3 } $\begin{array}{ll}\text { Temperature } \\
(\mathrm{K})\end{array}$ & $\begin{array}{ll}\text { Heating, } \\
80-450 \mathrm{~K}\end{array}$ \\
\hline 100 & 2.08 & $\begin{array}{l}\text { Cooling, } \\
450-80 \mathrm{~K}\end{array}$ \\
200 & 2.31 & 4.55 \\
450 & 2.72 & 4.23 \\
& & 2.72
\end{tabular}


Due to the phase transition observed when SION-7 is activated and transforms into SION-7a, the fluorescence emission of SION-7a was also investigated. Like SION-7 in the second and third thermal sequences, SION-7a exhibits a similar featureless excimer emission in the entire $80-450 \mathrm{~K}$ temperature range, and the emission profiles are reversible for at least three cycles of heating and cooling (Fig. $3 \mathrm{~b}$ and S13 $\dagger$ ). The colour of the fluorescence changes from yellow-green back and forth to yellow (Fig. 3d and S14 $\dagger$ ). The immersion of SION-7a in DMF does not lead to the recovery of the monomer emission of the resultant material (Fig. S15†).

Interestingly, while kept in a relatively wide temperature range of $80-200 \mathrm{~K}$, as-made SION-7 displays structured monomer-like spectrum, which red-shifts and decreases in intensity when the temperature is increased, and blue-shifts and increases in intensity when the temperature is decreased (Fig. 4a and S16†). Its colour changes reversibly from deep to light blue, but never surpasses the left bottom part of the CIE1931 chromaticity diagram (Fig. 4b and S17†). Therefore, be keeping the material in a low-temperature range, monomer emission from SION-7 can be retained.
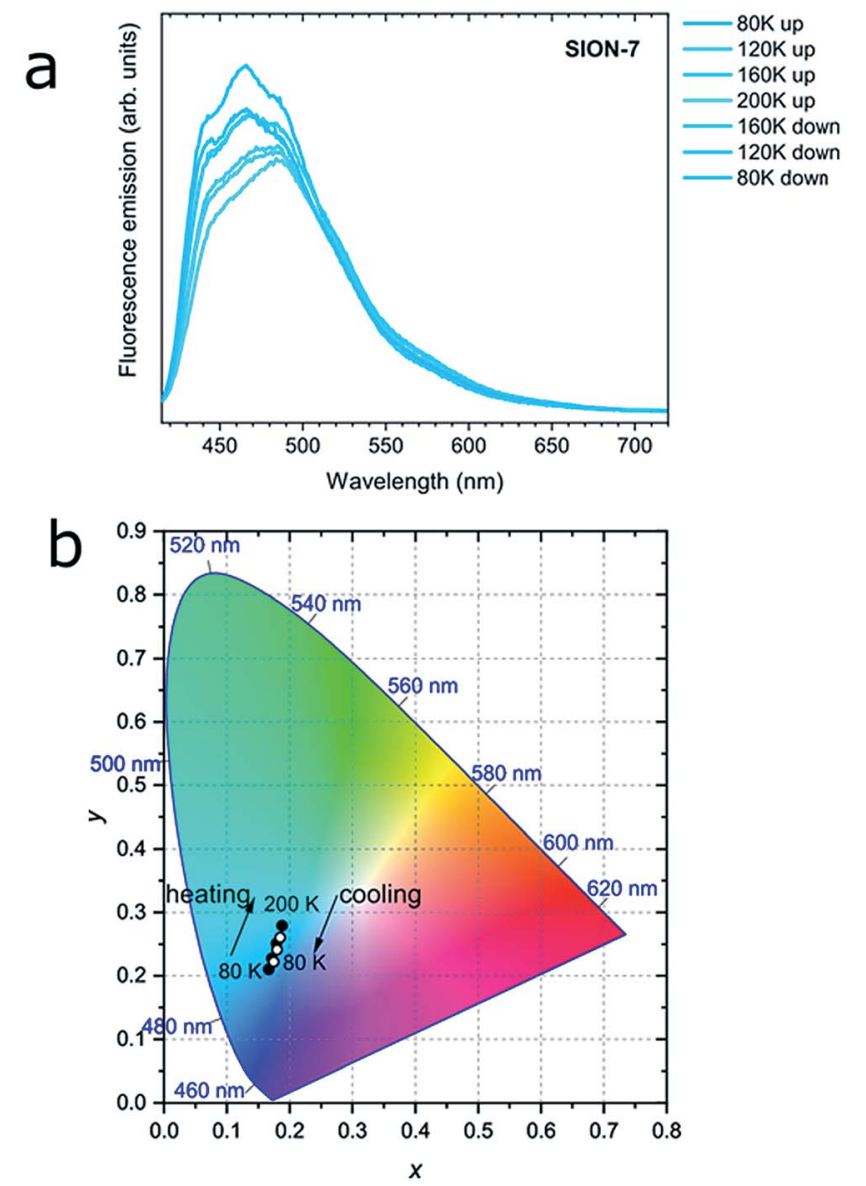

Fig. 4 (a) Fluorescence spectra of SION-7 measured in the 80-200 K temperature range on heating and cooling. (b) $\mathrm{ClE}-1931$ chromaticity diagram of the fluorescence from SION-7 during heating (filled circles) and cooling (empty circles) in the $80-200 \mathrm{~K}$ temperature range.
To elucidate the excimer formation in SION-7, VT SCXRD measurements were performed. As previously described, the structure of SION-7 consists of 2-dimensional layers of pairs of $\mathrm{HTBAPy}^{3-}$ ligands joined together by $\mathrm{Mg}_{3}$-clusters noncovalently stacked on the top of one another (Fig. 1c). Interestingly, the pyrene core planes spacing within the $\mathrm{Mg}_{3}$ bound layers $(4.752 \AA$ in the initial crystal structure measured at $100 \mathrm{~K}$ ) is greater than the spacing between planes of pyrene cores originating from two subsequent layers (3.561 $\mathrm{A})$. Since also the offset between the succeeding pyrene cores is greater within the layers than in between of them (Fig. 5a and S18a, $\left.\mathrm{b}^{\dagger}\right)$, we reason that the pyrene cores originating from two consecutive 2-dimensional layers interact with each other to give the excimer fluorescence. This spacing increases with temperature (by $0.24 \AA$ in the $100-400 \mathrm{~K}$ temperature range; Fig. S18c $\dagger$ ), and amounts to slightly higher values than the sum of the van der Waals radii of $\mathrm{C}(3.54 \AA) .{ }^{38}$ However, this observation only explains the excimer emission in SION-7a and in SION-7 during the second and third thermal sequence, but does not explain the monomer emission exhibited by the as-made SION-7. The clarification comes from the analysis of the pore content as a function of temperature. As aforementioned, there are two types of pores within the structure of SION-7, pore 1 and pore 2 . Pore 1 , situated at $x, 0,0.5$, is at the initial stage at $100 \mathrm{~K}$ filled with ca. $2 \mathrm{DMF}$ molecules, while pore 2, with the fractional coordinates of $x, 0.5,0$, encloses ca. 1 DMF molecule. As the temperature is increased, the total pore content changes to a limited extent up to $330 \mathrm{~K}$, and at this temperature a dramatic decrease in electron count inside pore 1 takes place (Fig. 5b). Above this point and on subsequent cooling, the content of this pore stays virtually invariant as it now comprises $c a$. 1 molecule of DMF. Simultaneously, the content of pore 2 amounts to ca. 1 DMF molecule throughout the entire thermal cycle (Fig. 5b), and the pore content analysis is consistent with the TGA result (Fig. $\mathrm{S} 5 \dagger$ ). It is reasonable that extra DMF molecules in pore 1 impede the pyrene-pyrene interactions hindering the formation of an excimer, which can be formed and show up in the emission spectra solely once the guest solvent molecules are released. Therefore, fluorescence of SION-7 is a physical phenomenon which is strongly dependent on the presence of the guest solvents, in analogy to spin crossover in $\mathrm{Fe}_{2}(\text { azpy })_{4}(\mathrm{NCS})_{4},{ }^{39}$ and compressibility in $\mathrm{Zn}(\text { niba })_{2}(\mathrm{OH})_{2} \cdot{ }^{40}$ Another structural feature that explains the excimer formation is the level of extended $\pi-\pi$ conjugation of the aromatic rings. Within each $\mathrm{HTBAPy}^{3-}$ excimer, the pyrene cores are parallel to each other, while the phenylene rings attached to them are positioned in a much less regular manner. As the temperature is increased, the values of dihedral angles between the phenylene rings originating from the neighbouring $\mathrm{HTBAPy}^{3-}$ within the excimer (captioned as C20-C40 and C30-C50 in Fig. 5a) decrease: $\angle \mathrm{C} 20 \mathrm{C} 40$ drops from $13.86^{\circ}$ at $100 \mathrm{~K}$ at the beginning of the thermal cycle to $9.85^{\circ}$ at $350 \mathrm{~K}$, while the corresponding initial and final values for $\angle \mathrm{C} 30 \mathrm{C} 50$ are $34.72^{\circ}$ and $4.37^{\circ}$, respectively (Fig. 5c). This implies that the phenylene rings effectively become more parallel towards each other (a dihedral angle of $0^{\circ}$ would 


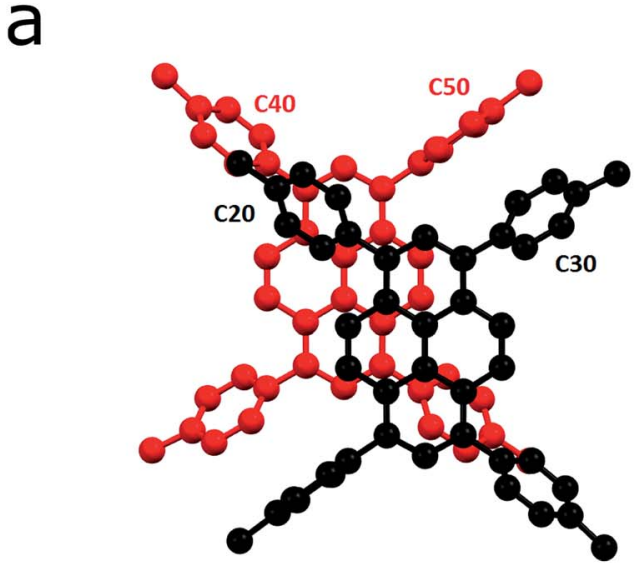

C

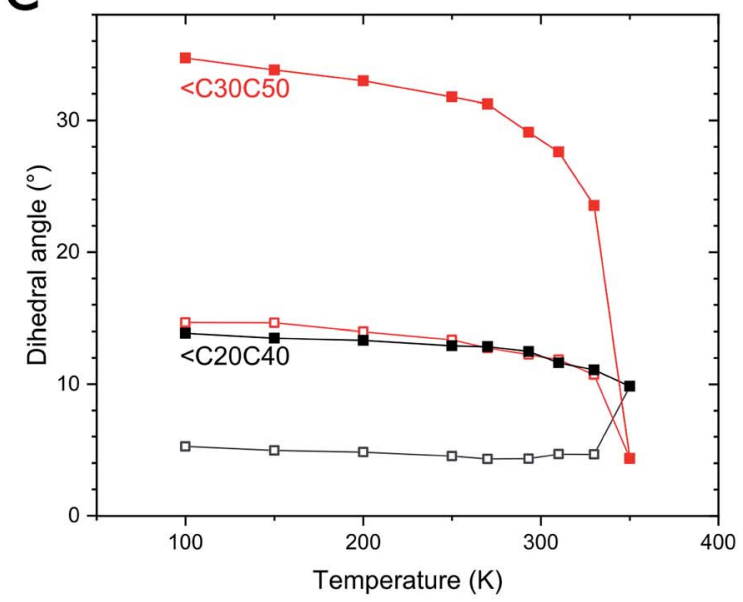

b

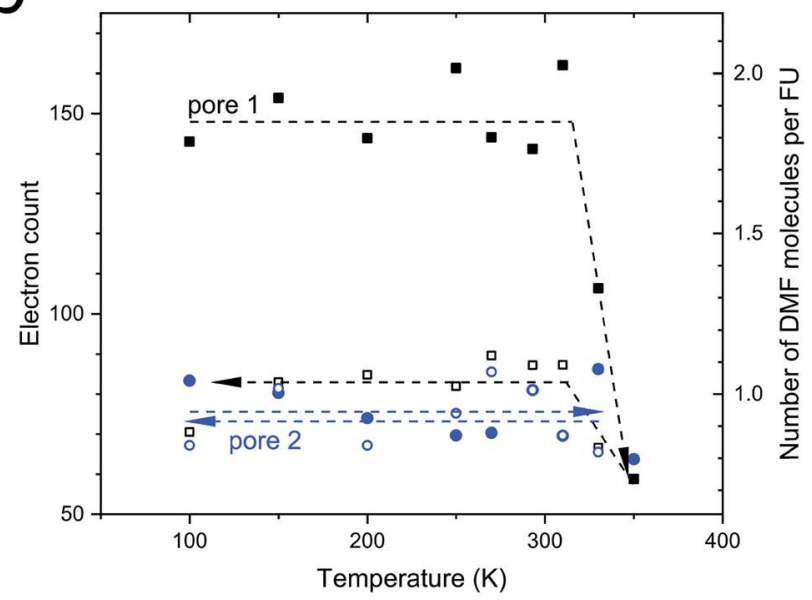

d

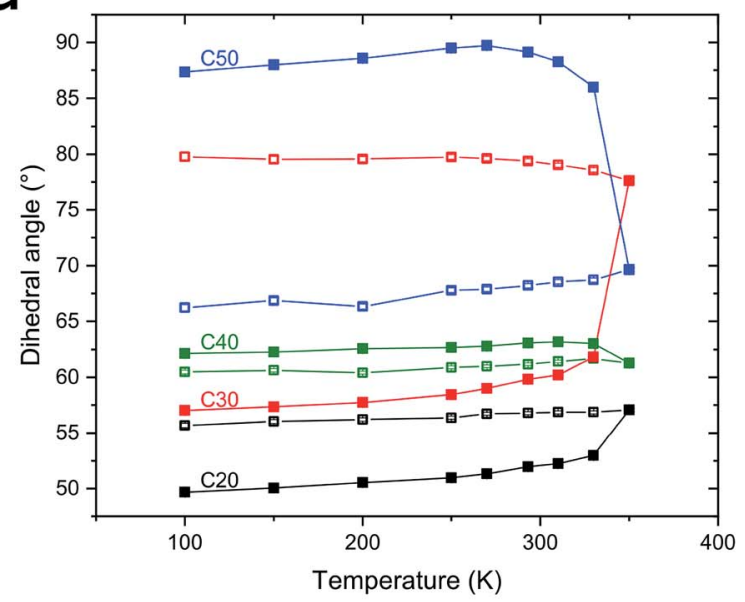

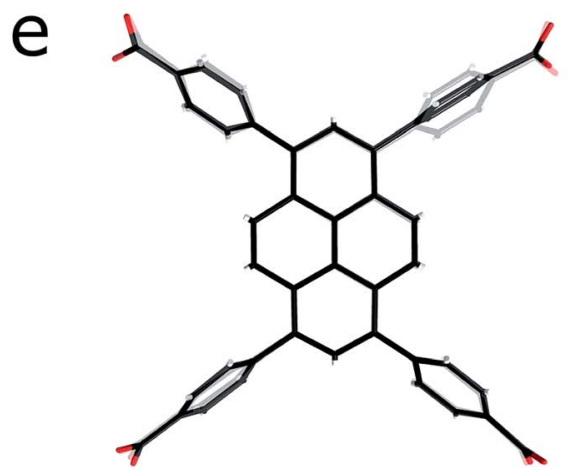

Fig. 5 (a) A pair of HTBAPy ${ }^{3-}$ ligands originating from two neighbouring 2-dimensional layers, forming an excimer. Phenylene rings are captioned. (b) Content of pore 1 and pore 2 of SION-7 expressed as electron count (left vertical axis) and the corresponding number of DMF molecules per formula unit (right vertical axis). (c) Dihedral angles between the phenylene rings originating from the neighbouring HTBAPy ${ }^{3-}$ within the excimer plotted as a function of temperature. (d) Dihedral angles between the pyrene core and the phenylene rings within each HTBAPy $^{3-}$ ligand. Full and empty symbols denote the heating and cooling regimes, respectively. (e) Superposition of the images of HTBAPy ${ }^{3-}$ derived from the structures at $100 \mathrm{~K}$ (opaque wireframe) and $350 \mathrm{~K}$ (bold wireframe).

signify a perfect parallelism), thus the interaction between them is more favourable. Moreover, the dihedral angles between the pyrene core and the phenylene rings within each HTBAPy $^{3-}$ ligand change in a multidirectional way with temperature (the angles C20-pyrene and C30-pyrene increase, C40-pyrene stays virtually invariant, while C50pyrene decreases, Fig. 5d), which may explain why slight changes in the fluorescence shift and intensity are still observed even after SION-7 undergoes the transition towards the excimer state. Superimposing the images of $\mathrm{HTBAPy}^{3-}$ 
derived from the structures at $100 \mathrm{~K}$ and $305 \mathrm{~K}$ emphasises the multidirectional way of phenylene-pyrene dihedral angle changes in the discussed temperature range (Fig. 5e).

\section{Conclusions}

SION-7, a MOF synthesised from the self-assembly of $\mathrm{Mg}^{2+}$ and $\mathrm{H}_{4} \mathrm{TBAPy}$, was found to be a platform suitable for an in-depth study of the interactions between pyrene derivative chromophores incorporated into the metal-organic framework. Noteworthy, it was found that the interchromophoric interactions in a pyrene-based MOF do not depend solely on the framework topology and the linker concentration, but can also be tuned by external stimuli. In particular, temperature was shown to dramatically change the mutual orientation of HTBAPy ${ }^{3-}$ ligands (enhanced parallelism of the phenylene rings originating form two neighbouring layers of HTBAPy ${ }^{3-}$ ligands plus multidirectional change of the phenylene-pyrene dihedral angles at elevated temperatures) and the pore content of SION-7 (at $100 \mathrm{~K}$ pore 1 is filled with approx. $2 \mathrm{DMF}$, and pore 2 with approx. 1 such molecule; upon heating up to $350 \mathrm{~K}$, the content of these pores changes to approx. 1 and 1 DMF molecule, respectively), which entails crucial changes in the fluorescence emission (a structured monomer emission at low temperatures transforms to a structureless excimer emission at high temperatures). Another important conclusion of this work is that the presence of simple guest molecules such as solvents plays an important role in the fluorescence emission of pyrenebased MOFs, and shall not be overlooked in future studies. Our study opens a new dimension for controlling the optical properties of porous materials since the colour of their emission can be regulated without the need of introducing additional chemical species. When integrated to a substrate, e.g. in form of a thin film, SION-7 could potentially serve as a temperature sensor for cryogenic environments; when temperatures higher than cryogenic were attained, such a sensor would dramatically change its colour.

\section{Conflicts of interest}

There are no conflicts to declare.

\section{Acknowledgements}

T. N. N. and K. C. S. thank Swiss National Science Foundation (SNSF) for funding under the Ambizione Energy Grant no. PZENP2_166888 and the National Center of Competence in Research (NCCR), Materials' Revolution: Computational Design and Discovery of Novel Materials (MARVEL) - DD4.5. The access to the BM01 and BM31 Swiss-Norwegian Beamlines at the ESRF, Grenoble, France, is gratefully acknowledged. A. G. thanks Prof. Vladislav A. Blatov and Ms Samantha L. Anderson for fruitful discussions, and Dr Joël Teuscher for the quantum yield measurement.

\section{References}

1 N. J. Turro, V. Ramamurthy and J. C. Scaiano, Principles of Molecular Photochemistry: An Introduction, University Science Books, Sausalito, CA, 2009.

2 G. K. Bains, S. H. Kim, E. J. Sorin and V. Narayanaswami, Biochemistry, 2012, 51, 6207-6219.

3 (a) W. Cho, H. J. Lee, G. Choi, S. Choi and M. Oh, J. Am. Chem. Soc., 2014, 136, 12201-12204; (b) D. Ananias, A. D. G. Firmino, R. F. Mendes, F. A. A. Paz, M. Nolasco, L. D. Carlos and J. Rocha, Chem. Mater., 2017, 29, 95479554; (c) R. Dalapati and S. Biswas, Sens. Actuators, B, 2017, 239, 759-767; (d) H. R. Fu, X. X. Wu, L. F. Ma, F. Wang and J. Zhang, ACS Appl. Mater. Interfaces, 2018, 10, 1801218020; (e) T. N. Nguyen, F. M. Ebrahim and K. C. Stylianou, Coord. Chem. Rev., 2018, 377, 259-306.

4 C. Wei, M. Gao, F. Hu, J. Yao and Y. S. Zhao, Adv. Opt. Mater., 2016, 4, 1009-1014.

5 T. Förster, Angew. Chem., Int. Ed. Engl., 1969, 8, 333-343.

6 (a) J. Ferguson, J. Chem. Phys., 1958, 28, 765-768; (b) B. Stevens, Spectrochim. Acta, 1962, 18, 439-448; (c) R. Seyfang, E. Betz, H. Port, W. Schrof and H. C. Wolf, J. Lumin., 1985, 34, 57-62; (d) F. M. Winnik, Chem. Rev., 1993, 93, 587-614.

7 (a) G. J. McManus, J. J. Perry, M. Perry, B. D. Wagner and M. J. Zaworotko, J. Am. Chem. Soc., 2007, 129, 9094-9101; (b) S. K. Rajagopal, V. S. Reddy and M. Hariharan, CrystEngComm, 2016, 18, 5089-5094; (c) P. Deria, J. Yu, T. Smith and R. P. Balaraman, J. Am. Chem. Soc., 2017, 139, 5973-5983; (d) J. Yu, J. Park, A. Van Wyk, G. Rumbles and P. Deria, J. Am. Chem. Soc., 2018, 140, 10488-10496.

8 (a) K. C. Stylianou, R. Heck, S. Y. Chong, J. Bacsa, J. T. A. Jones, Y. Z. Khimyak, D. Bradshaw and M. J. Rosseinsky, J. Am. Chem. Soc., 2010, 132, 4119-4130; (b) K. C. Stylianou, J. Rabone, S. Y. Chong, R. Heck, J. Armstrong, P. V. Wiper, K. E. Jelfs, S. Zlatogorsky, J. Bacsa, A. G. McLennan, C. P. Ireland, Y. Z. Khimyak, K. M. Thomas, D. Bradshaw and M. J. Rosseinsky, J. Am. Chem. Soc., 2012, 134, 20466-20478; (c) J. E. Mondloch, W. Bury, D. Fairen-Jimenez, S. Kwon, E. J. DeMarco, M. H. Weston, A. A. Sarjeant, S. T. Nguyen, P. C. Stair, R. Q. Snurr, O. K. Farha and J. T. Hupp, J. Am. Chem. Soc., 2013, 135, 10294-10297; (d) C.-W. Kung, T. C. Wang, J. E. Mondloch, D. Fairen-Jimenez, D. M. Gardner, W. Bury, J. M. Klingsporn, J. C. Barnes, R. Van Duyne, J. F. Stoddart, M. R. Wasielewski, O. K. Farha and J. T. Hupp, Chem. Mater., 2013, 25, 5012-5017; (e) R.-J. Li, M. Li, X.-P. Zhou, D. Li and M. O'Keeffe, Chem. Commun., 2014, 50, 40474049; (f) R.-J. Li, M. Li, X.-P. Zhou, S. W. Ng, M. O'Keeffe and D. Li, CrystEngComm, 2014, 16, 6291-6295; $(g)$ P. Li, N. A. Vermeulen, X. Gong, C. D. Malliakas, J. F. Stoddart, J. T. Hupp and O. K. Farha, Angew. Chem., Int. Ed., 2016, 55, 10358-10362; (h) V. A. Milichko, S. V. Makarov, A. V. Yulin, A. V. Vinogradov, A. A. Krasilin, E. Ushakova, V. P. Dzyuba, E. Hey-Hawkins, E. A. Pidko and P. A. Belov, Adv. Mater., 2017, 29, 1606034; (i) A. Gładysiak, K. S. Deeg, 
I. Dovgaliuk, A. Chidambaram, K. Ordiz, P. G. Boyd, S. M. Moosavi, D. Ongari, J. A. R. Navarro, B. Smit and K. C. Stylianou, ACS Appl. Mater. Interfaces, 2018, 10, 36144-36156; (j) A. Gładysiak, T. N. Nguyen, M. Spodaryk, J.-H. Lee, J. B. Neaton, A. Züttel and K. C. Stylianou, Chem.-Eur. J., 2019, 25, 501-506.

9 (a) O. M. Yaghi, M. O'Keeffe, N. W. Ockwig, H. K. Chae, M. Eddaoudi and J. Kim, Nature, 2003, 423, 705-714; (b) H. Furukawa, N. Ko, Y. B. Go, N. Aratani, S. B. Choi, E. Choi, A. Ö. Yazaydin, R. Q. Snurr, M. O'Keeffe, J. Kim and O. M. Yaghi, Science, 2010, 329, 424-428; (c) C. Zhou, L. Longley, A. Krajnc, G. J. Smales, A. Qiao, I. Erucar, C. M. Doherty, A. W. Thornton, A. J. Hill, C. W. Ashling, O. T. Qazvini, S. J. Lee, P. A. Chater, N. J. Terrill, A. J. Smith, Y. Yue, G. Mali, D. A. Keen, S. G. Telfer and T. D. Bennett, Nat. Commun., 2018, 9, 5042.

10 M. Li, D. Li, M. O'Keeffe and O. M. Yaghi, Chem. Rev., 2014, 114, 1343-1370.

11 Y. He, F. Chen, B. Li, G. Qian, W. Zhou and B. Chen, Coord. Chem. Rev., 2018, 373, 167-198.

12 L. Wang, D. W. Agnew, X. Yu, J. S. Figueroa and S. M. Cohen, Angew. Chem., Int. Ed., 2018, 57, 511-515.

13 Y. Zhang, S. Yuan, G. Day, X. Wang, X. Yang and H.-C. Zhou, Coord. Chem. Rev., 2018, 354, 28-45.

14 (a) M. Andrzejewski and A. Katrusiak, J. Phys. Chem. Lett., 2017, 8, 279-284; (b) M. Andrzejewski and A. Katrusiak, J. Phys. Chem. Lett., 2017, 8, 929-935.

15 (a) B. V. Harbuzaru, A. Corma, F. Rey, P. Atienzar, J. L. Jordá, H. García, D. Ananias, L. D. Carlos and J. Rocha, Angew. Chem., 2008, 120, 1096-1099; (b) Z. Hu, B. J. Deibert and J. Li, Chem. Soc. Rev., 2014, 43, 5815-5840; (c) N. B. Shustova, A. F. Cozzolino, S. Reineke, M. Baldo and M. Dincă, J. Am. Chem. Soc., 2013, 135, 13326-13329; (d) E. A. Dolgopolova, A. M. Rice, C. R. Martin and N. B. Shustova, Chem. Soc. Rev., 2018, 47, 4710-4728; (e) F. M. Ebrahim, T. N. Nguyen, S. Shyshkanov, A. Gładysiak, P. Favre, A. Zacharia, G. Itskos, P. J. Dyson and K. C. Stylianou, J. Am. Chem. Soc., 2019, 141, 3052-3058.

16 P. Müller, F. M. Wisser, P. Freund, V. Bon, I. Senkovska and S. Kaskel, Inorg. Chem., 2017, 56, 14164-14169.

17 L. Wang, Y. Ye, Z. Li, Q. Lin, J. Ouyang, L. Liu, Z. Zhang and S. Xiang, Cryst. Growth Des., 2017, 17, 2081-2089.

18 M. Andrzejewski, N. Casati and A. Katrusiak, Dalton Trans., 2017, 46, 14795-14803.

19 Y. Cui, Y. Yue, G. Qian and B. Chen, Chem. Rev., 2012, 112, 1126-1162.

20 (a) M. Gutiérrez, F. Sánchez and A. Douhal, Chem.-Eur. J., 2016, 22, 13072-13082; (b) W.-M. Liao, J.-H. Zhang,
S.-Y. Yin, H. Lin, X. Zhang, J. Wang, H.-P. Wang, K. Wu, Z. Wang, Y.-N. Fan, M. Pan and C.-Y. Su, Nat. Commun., 2018, 9, 2401.

21 V. Dyadkin, P. Pattison, V. Dmitriev and D. Chernyshov, J. Synchrotron Radiat., 2016, 23, 825-829.

22 Rigaku Oxford Diffraction, 1.171.38.43 edn, 2015.

23 G. Sheldrick, Acta Crystallogr., Sect. A: Found. Adv., 2015, 71, 3-8.

24 G. Sheldrick, Acta Crystallogr., Sect. C: Struct. Chem., 2015, 71, 3-8.

25 O. V. Dolomanov, L. J. Bourhis, R. J. Gildea, J. A. K. Howard and H. Puschmann, J. Appl. Crystallogr., 2009, 42, 339-341.

26 V. A. Blatov, A. P. Shevchenko and D. M. Proserpio, Cryst. Growth Des., 2014, 14, 3576-3586.

27 P. van der Sluis and A. L. Spek, Acta Crystallogr., Sect. A: Found. Crystallogr., 1990, 46, 194-201.

28 J. Rodríguez-Carvajal, Phys. B, 1993, 192, 55-69.

29 S. S. Park, C. H. Hendon, A. J. Fielding, A. Walsh, M. O'Keeffe and M. Dincă, J. Am. Chem. Soc., 2017, 139, 3619-3622.

30 (a) E. H. H. Chow, F. C. Strobridge and T. Friščić, Chem. Commun., 2010, 46, 6368-6370; (b) M. Kang, T. Liu, X. Wang, D. Luo, R. Li and Z. Lin, Inorg. Chem. Commun., 2014, 44, 155-158.

31 (a) F. Gándara, E. Gutiérrez-Puebla, M. Iglesias, N. Snejko and M. Á. Monge, Cryst. Growth Des., 2010, 10, 128-134; (b) L. Lü, B. Mu, C.-X. Li and R.-D. Huang, J. Solid State Chem., 2016, 234, 93-102.

32 B. Cui, H. Sun, Y. Xu, L. Duan and Y.-M. Li, Tetrahedron, 2017, 73, 6754-6762.

33 A. Balena, A. Perulli, M. Fernandez, M. L. De Giorgi, G. Nedelcu, M. V. Kovalenko and M. Anni, J. Phys. Chem. C, 2018, 122, 5813-5819.

34 H. Port, P. Fischer and R. Seyfang, J. Lumin., 1990, 45, 260262.

35 (a) Q. Zhang, J. Su, D. Feng, Z. Wei, X. Zou and H.-C. Zhou, J. Am. Chem. Soc., 2015, 137, 10064-10067; (b) C.-X. Chen, Z.-W. Wei, Y.-N. Fan, P.-Y. Su, Y.-Y. Ai, Q.-F. Qiu, K. Wu, S.-Y. Yin, M. Pan and C.-Y. Su, Chem, 2018, 4, 2658-2669.

36 S. Khatua, S. Goswami, S. Biswas, K. Tomar, H. S. Jena and S. Konar, Chem. Mater., 2015, 27, 5349-5360.

37 X. Du, R. Fan, J. Fan, L. Qiang, Y. Song, Y. Dong, K. Xing, P. Wang and Y. Yang, Inorg. Chem. Front., 2016, 3, 14801490.

38 S. Alvarez, Dalton Trans., 2013, 42, 8617-8636.

39 G. J. Halder, C. J. Kepert, B. Moubaraki, K. S. Murray and J. D. Cashion, Science, 2002, 298, 1762.

40 W. Cai, A. Gładysiak, M. Anioła, V. J. Smith, L. J. Barbour and A. Katrusiak, J. Am. Chem. Soc., 2015, 137, 9296-9301. 